\title{
Acoustic Emission for the detection of shaft-to- seal rubbing in large power generation turbines
}

\author{
M. Leahy ${ }^{1}$, D. Mba' ${ }^{1}$, P. Cooper ${ }^{2}$, A. Montgomery ${ }^{2}$, D. Owen² \\ 'School of Engineering, Cranfield University, Cranfield, Beds, MK43 OAL, UK. \\ ${ }^{2}$ Alstom Power, Rugby, UK.
}

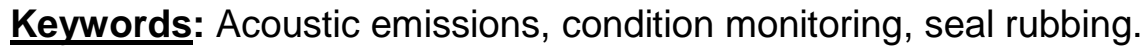

\begin{abstract}
An empirical investigation is undertaken in order to assess the potential of the AE technique for the detection of seal-to-rotor rubbing in steam turbines. Rubbing was induced at various axial locations along a $4 \frac{1}{2}$ tonne test rotor, rotating at $3000 \mathrm{rpm}$ and supported by $7 "(178 \mathrm{~mm})$ journal bearings. This paper examines the capabilities of bearing mounted AE transducers for the detection of seal-torotor rubbing.
\end{abstract}

\section{Introduction}

Rotor-to-stator rubbing is a secondary phenomenon that is usually the result of a mechanism which perturbs the "normal operating conditions" (Muszynska, 1989). The primary causes of rubbing are imbalance, stator/casing motion and dynamic fluid forces. Predicting and preventing the rubbing phenomenon has attracted the attention of many researchers and has continued to provide a large incentive for the use of condition monitoring techniques to detect the early stages of shaft seal rubbing. Rotor-Stator rubbing may be broadly classified as either partial or continuous. The former type describes brief intermittent contacts and the latter describes more sustained contact between rotor and stator.

Vibration diagnosis still remains the most widely used method for detecting rubbing in rotating machinery. In power generation turbines, rubbing is most often evident through changes in the amplitude and phase of the $1 \mathrm{X}$ (rotating frequency) vibration component. These changes result from the bending of the shaft due to circumferentially uneven heating caused by the frictional contact. However, it can be difficult to identify rubs using vibrations as the $1 \mathrm{X}$ frequency components can also be affected by a number of other factors. In order to perform a proper diagnosis of machinery suspected with rubs, the analyst is expected to have a very good knowledge of rotor dynamics. In addition, even when vibration analysis is capable of identifying rub conditions in machinery, it is frequently not capable of reliably locating the precise source of the fault, particularly on power generation units where several turbine units are coupled together. This is primarily due to the modal characteristics of the coupled units. In the light of this, some studies have identified high frequency acoustic emissions monitoring as a more sensitive and direct approach for rotor-stator rubbing. This assumes that the frictional rubbing between the metallic rotor and stator components causes a release of high frequency Acoustic Emission (AE) that can propagate from the rub source to the receiving sensor attached remotely at the bearing housing. This paper assesses the applicability of AE for detecting the presence of rubbing through a series of tests on a large rotating test rig. 


\section{Acoustic Emission in turbo machinery}

Acoustic Emission (AE) is a term describing a class of phenomena whereby transient elastic waves are generated by the rapid release of energy from localized sources within or on the surface of a material. In the application to rotating machinery monitoring, AE are defined as elastic waves generated by the interaction of two media in relative motion. Sources of AE in rotating machinery include impacting, friction, turbulence, cavitation, leakage, etc. For instance, the interaction of surface asperities of a rotating shaft and a stationary seal will result in the generation of acoustic emissions. These emissions propagate on the surface of the material as Rayleigh waves and the displacement of these waves is measured with an $\mathrm{AE}$ sensor. The basic physical mechanisms responsible for the generation of AE during metallic rub contact involve phenomena of friction and plastic deformation. The typical frequency range associated with $\mathrm{AE}$ is between $100 \mathrm{kHz}$ to $1 \mathrm{MHz}$.

The published work of Sato (Sato, 1990) could be considered the first that directly addressed shaftseal rubbing in large rotating machinery with AE. Hall (Hall and Mba, 2004) investigated the use of signal analysis techniques for the application of AE to the diagnosis of seal to rotor rubs within steam turbines. A very good example of the potential for AE in the condition monitoring of steam turbines is given by Mba (Mba et al., 2004), who attached piezo-electric AE transducers to a turbine which was suffering from excessive shaft vibration thought to be due to seal rubbing. The machine in question had two low pressure steam turbines and a combined high-pressure / intermediatepressure steam turbine connected to the same shaft. The transducers were mounted to the seal casings at each end of the low pressure turbines. It is reported that bursts of waveforms were detected in three locations. The characteristics of the bursts and the presence of a coupling between the turbines led the author to conclude that both low-pressure turbines were suffering from rotor to stator rubbing. As the transducers were mounted to the seal casings, with no easy transmission path to other potential rub sources, it is thought that the rubs are most likely to be due to seal-to-rotor rubbing. Indeed, the rubbing was successfully halted by increasing the condenser pressure. This has the effect of raising the exhaust steam temperature, which would in turn increase the clearance between seals and rotor. Further data capture from the transducers yielded pure white noise, with no bursts of wave forms or modulation.

\section{Experimental programme and set-up}

An experimental programme was carried out to investigate further the suitability of AE for identifying seal rubbing. The test rig used for the programme consisted of a $4 \frac{1}{2}$ tonne, $2 \mathrm{~m}$ long rotor, supported at each end by a 7" $(178 \mathrm{~mm})$ hydrodynamic journal bearing. The rotor and bearings were installed within a vacuum chamber with an externally mounted electric motor. Although the speed of the motor was variable, the experiments were undertaken at $3000 \mathrm{rpm}$ as this is the speed at which most power generation steam turbines run throughout Europe.

In order to simulate seal to rotor rubs, replica seals were machined from stainless steel and installed within assemblies, which convert the angular motion from a stepper motor into linear motion, allowing the seals to be pressed against the rotor. Four seal units were used, each mounted at a different location along the rotor (Fig. 1). 


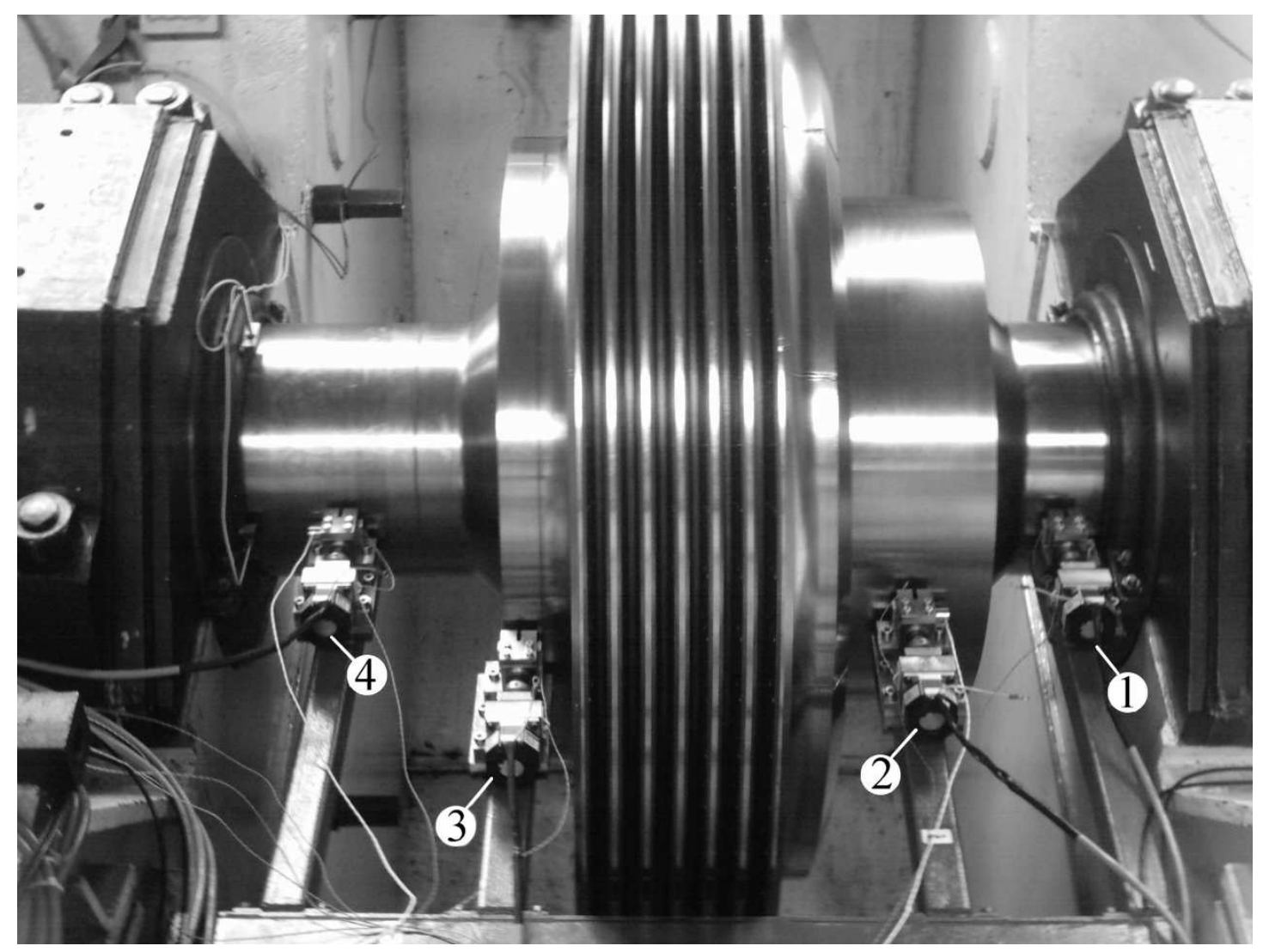

Figure 1: Test rig with the vacuum chamber lid removed. Drive-end is on the right.

The fin geometry of the seals is considered to be a good approximation to that used for the seals in steam turbines. The stepper motors have a resolution of 4000 steps per revolution, which when combined with a thread pitch of $1.5 \mathrm{~mm}$, theoretically allows the seals to be moved in linear steps of $375 \mathrm{\eta m}$. In practice the minimum linear step size used was $0.1 \mathrm{~mm}$. In order to achieve such accuracy, a spring was incorporated into the shaft assembly of the seal units to eliminate any slack in the thread (Fig. 2).

The stepper motors were driven by a Parker XLi-25 driver unit, controlled via the serial port of a PC using the Easi-Tools software supplied with the stepper drive. The driver unit can only control one stepper motor at a time. In order to operate different stepper motors, the stepper drive must be powered down and the stepper motor cables exchanged. The implication of this is that only one seal can be made to rub at a time.

The stepper motors are not designed to sustain axial loads, hence a thrust bearing has been incorporated into the seal units (Fig. 2), with the stepper motors connected to the shafts via flexible couplings. Seal guides were mounted above and below the seals to ensure that the seals were not displaced from their intended positions by the inertia of the rotating shaft once contact was made. Thermo-couples were affixed to the seals to allow their temperature to be monitored, reducing the risk of damage to both seals and rotor.

It was unknown whether the $\mathrm{AE}$ transducers mounted on the bearings would be able to detect rubbing induced by the seals. A possibility was that the rub signatures would be buried in the background $\mathrm{AE}$ noise generated by the normal operation of the test rig. As a precaution, $\mathrm{AE}$ transducers were mounted directly to the seals to ensure that a rub could be detected as soon as it was initiated. This was imperative from a safety point of view as seal-to-rotor contact could not be 
confirmed visually as all tests were carried out with the lid to the test chamber in place. The AE transducers were bonded to the seals with Cyno-acrylate. This adhesive was chosen for this purpose as it forms a strong bond, is acoustically benign and can withstand temperatures in excess of $100^{\circ} \mathrm{C}$. The AE transducers mounted to the bearing casings were affixed with magnetic clamps and marine grease was used as the couplant.

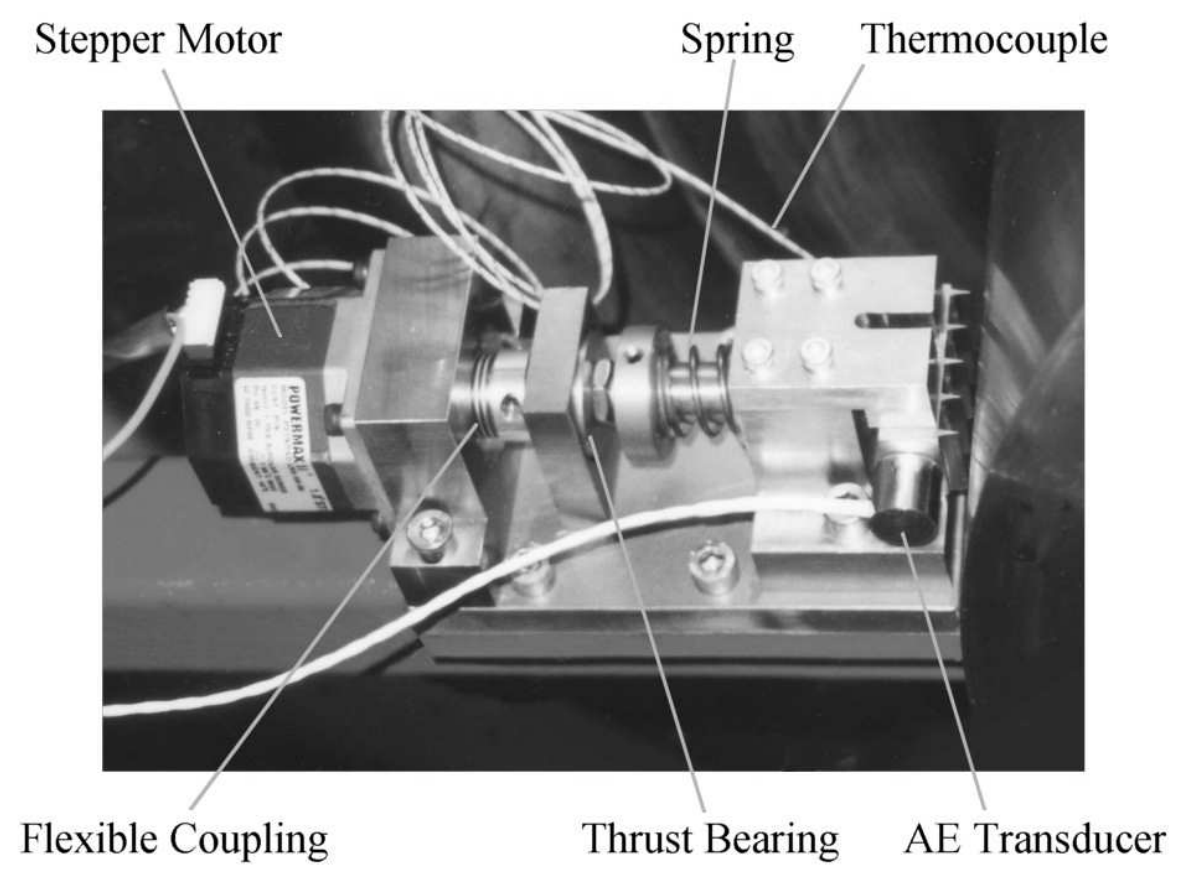

Figure 2: One of the seal units

\section{Data Acquisition System}

Physical Acoustics Corporation WD transducers were employed. These are differential broadband piezoelectric transducers with a bandwidth of $100 \mathrm{KHz}-1 \mathrm{MHz}$. The $\mathrm{AE}$ transducers were connected to variable gain pre-amplifiers $(20,40$ and $60 \mathrm{~dB})$, which were in turn connected to a ruggedised PC containing three Physical Acoustics Corporation PCI-2 acquisition cards. Continuous AE ASL (Average Signal Level), which gives the AE signal magnitude in terms of decibels, was calculated in real time by the analogue-to-digital converter (ADC) controlling software. This software employed a hardware accelerator to perform calculations in real time for a programmable time interval set by the user, $10 \mathrm{~ms}$ in this instance, and a sampling interval of $10 \mathrm{~ms}$ was employed. Anti-aliasing filters were also employed prior to the ADC.

The primary safety concern during the tests was that the local heating of the rotor caused by prolonged seal-to-rotor rubs could result in bowing of the shaft. This could cause severe vibration and damage to the machine. With this in mind, the shaft vibrations in both the horizontal and the vertical directions were measured in real time along with the bearing oil and white metal temperatures, oil pressure and artificial seal temperatures.

\section{Results and discussion}

Until it was verified that the bearing mounted transducers could detect rubbing between the replica seals and the shaft, one of the AE acquisition channels was connected to the transducer affixed to 
the seal that was inducing the rub. The bearing transducers were connected to the following channels:

Channel 1 - Bearing cap, drive end.

Channel 2 - Bearing cap, non-drive end.

With the seals at their datum positions, a $5 \mathrm{~mm}$ gap existed between the fin tips and the rotor. Seal 1 was moved towards the rotor in steps of $1 \mathrm{~mm}$ until the fin tips were $1 \mathrm{~mm}$ away from the rotor. The step size was reduced to $0.1 \mathrm{~mm}$ and motion continued until contact was achieved. Contact was characterised by a dramatic increase in acoustic emission activity at the seal transducer accompanied by lesser but still significant rises in the activity at the bearing transducers (Fig. 3 and 4). After initial contact, the rubs were allowed to continue for several seconds. It was seen that after the large initial rise in AE activity associated with initial contact, the AE activity gradually reduced with time. This was due to a continuous reduction in contact pressure as the seal and rotor wore. Several rubs were initiated before the seal was finally backed off to its datum and the test repeated for the other seals.

It was found that both seal and bearing mounted transducers could detect the onset of rubbing induced by each of the four seals. It was also found that the best performance was achieved with the pre-amplifiers set to $20 \mathrm{~dB}$ gain. The responses from the bearing transducers were equally as pronounced when the inboard seals (seals 2 and 3) initiated rubbing as when the outboard seals (seals 1 and 4) did (see Fig. 3 and 4), despite the longer transmission path. The typical increase in ASL levels at the bearings, due to the induced rubbing, was approximately $30 \%$.

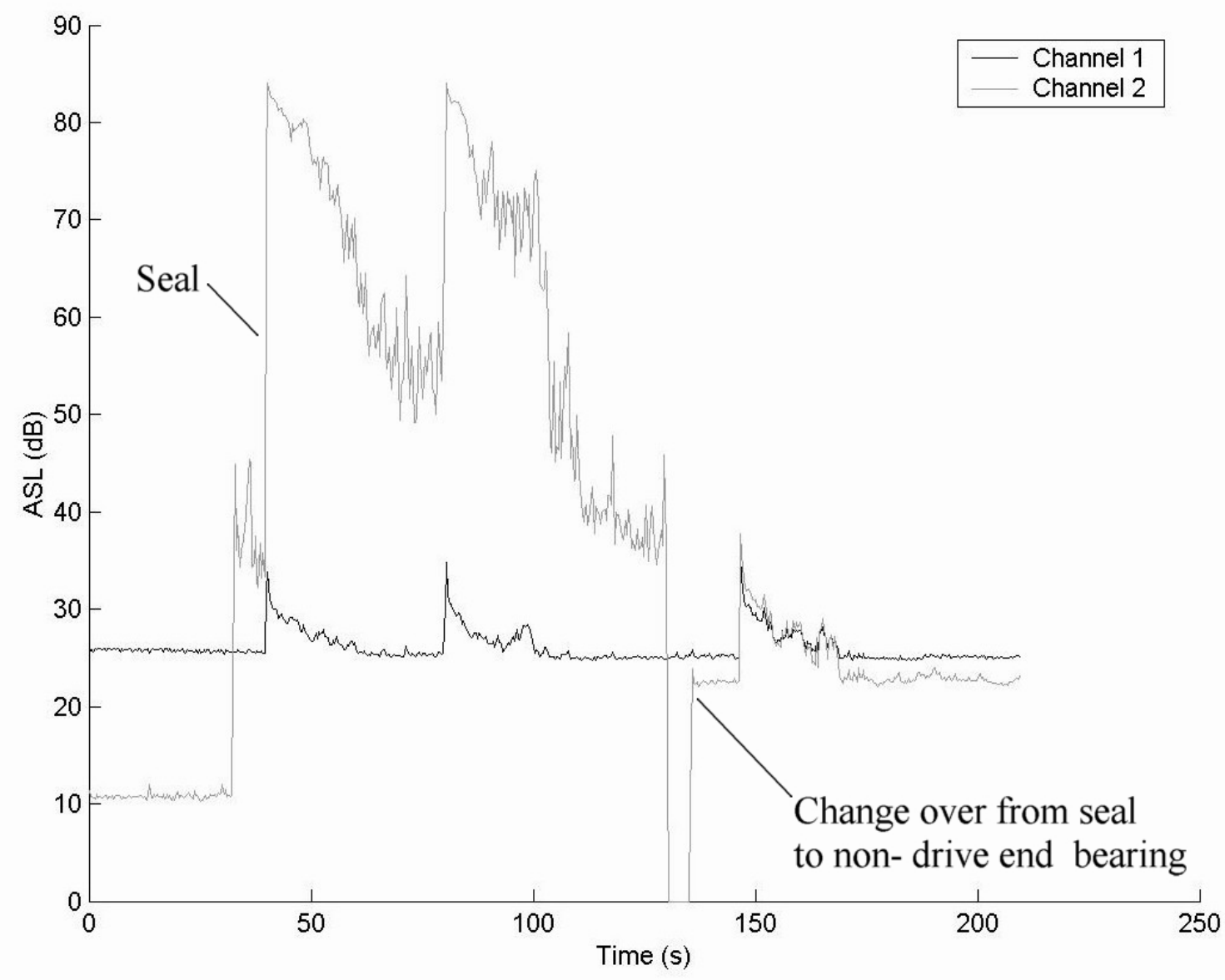

Figure 3: Rubbing between seal 2 and the rotor. Seal transducer swapped for bearing transducer at approximately 135 seconds into the test. 


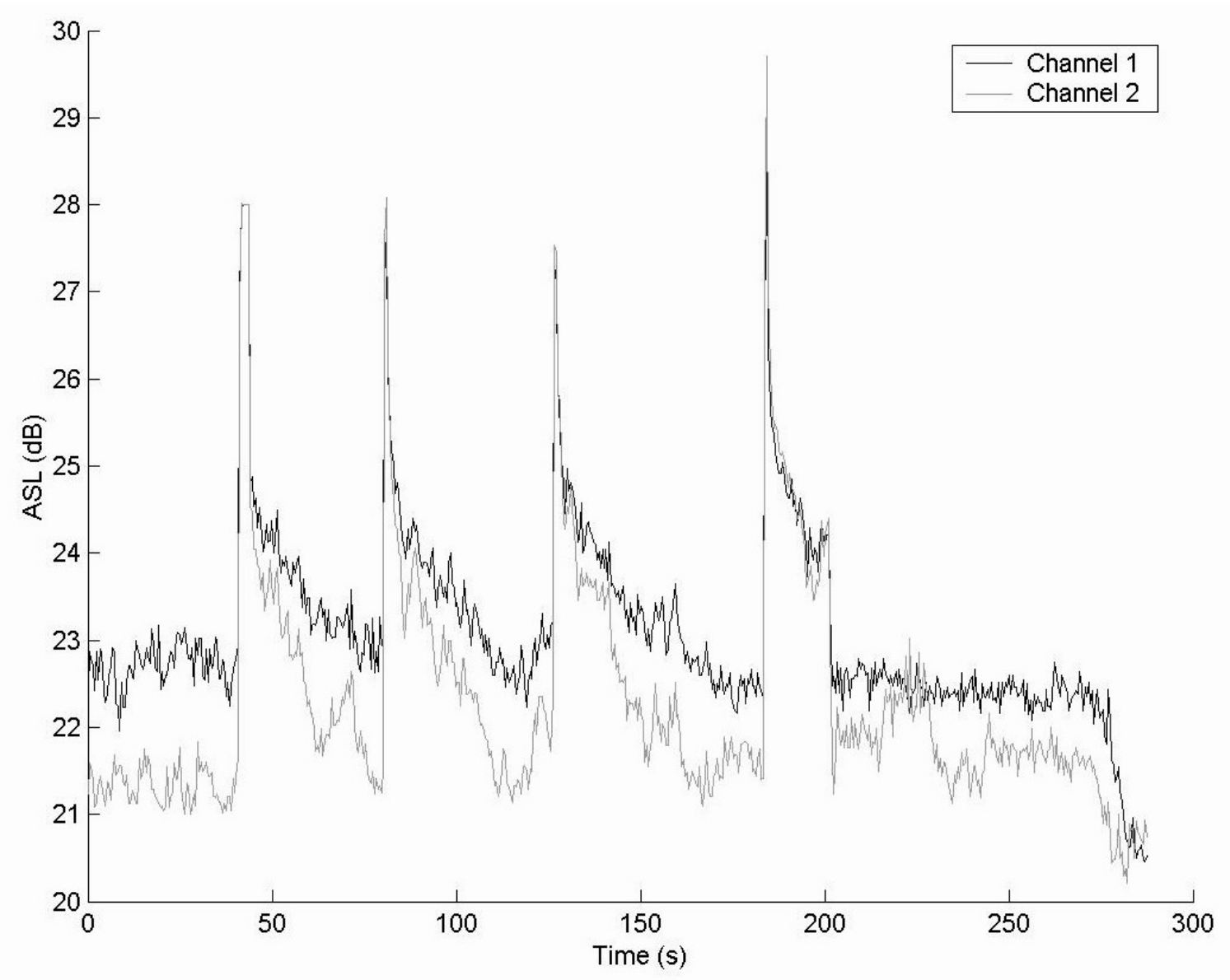

Figure 4: Rubbing between seal 1 and the rotor.

\section{Conclusions}

This paper has shown that it is possible to use acoustic emission monitoring techniques with bearing mounted transducers to detect seal-to-rotor rubs on a $4 \frac{1 / 2}{2}$ tonne test rotor running at $1500 \mathrm{rpm}$ and $3000 \mathrm{rpm}$ on hydrodynamic journal bearings. This opportunity ought to be exploited as it offers a complimentary tool for monitoring power generation turbines.

\section{References}

Hall L. D., and Mba, D., (2004) "Acoustic emissions diagnosis of rotor-stator rubs using the KS statistic", Mechanical Systems and Signal Processing, Vol. 18, No. 4, pp. 849-868.

Mba, D., Cooke, A., Roby, D., Hewitt, G., (2004) "Detection of shaft-seal rubbing in large-scale power generation turbines with Acoustic Emissions; Case study", Journal of Power and Energy Part A, I Mech E, Vol. 218, No. 2, pp. 71-82.

Muszynska, A., (1989) "Rotor-Stationary element rub-related vibration phenomena in rotating machinery-Literature Survey", The Shock and Vibration Digest, Vol. 121, No. 3, pp. 3-11.

Sato, I., (1990) "Rotating Machinery Diagnosis with Acoustic Emission Techniques", Electrical Engineering in Japan, Vol. 110, No. 2. 